\title{
JURISPRUDENCIA AMBIENTAL DE LA REGIÓN DE MURCIA (SEGUNDO SEMESTRE 2017)
}

\author{
EdUARDO SALAZAR ORTUÑO \\ Abogado \\ Profesor asociado \\ Universidad de Murcia
}


Sumario: 1. El desenlace jurídico-criminal ante la Audiencia Provincial del "caso Zerrichera". 2. El fracaso de la jurisdicción penal ante la contaminación del Río Segura a su paso por la ciudad de Murcia a finales del siglo XX.

De entre la producción jurisprudencial del segundo semestre de 2017 destacan dos resoluciones judiciales en el ámbito penal que se ocupan de sendos conflictos o casos ambientales de gran calado en la sensibilidad colectiva de la sociedad murciana y que se han resuelto de manera desigual. Nos ocuparemos de analizar en profundidad a través la Sentencia que ha finalizado en la Audiencia Provincial un caso paradigmático de corrupción en un asunto medioambiental y urbanístico acaecido en la Administración regional murciana, para posteriormente acudir a uno de los primeros casos de delito ecológico planteado en los tribunales murcianos, denunciado allá por el año 1999, que se ha resuelto de forma insatisfactoria en fechas recientes.

\section{EL DESENLACE JURÍDICO-CRIMINAL ANTE DE LA AUDIENCIA PROVINCIAL DEL "CASO ZERRICHERA".}

Si existe un caso que sirva para retratar los mecanismos y tentáculos procedimentales, el modus operandi, de la corrupción urbanística y ambiental en la Región de Murcia, ese es el "caso Zerrichera" o "Cerrichera". Recibe el nombre de la finca de 146 hectáreas que, incluida en diversas categorías de espacios naturales, pretendió ser urbanizada para dar cobijo a cerca de 4.000 viviendas, una población de 10.000 habitantes y un campo de golf, por parte de unos propietarios privados, que gozaron de un trato privilegiado de la Administración murciana, en cuanto a la tramitación urgente y singular de los procesos administrativos necesarios para la reclasificación de los terrenos y posterior transformación de la realidad física y biológica de la finca.

Afortunadamente en enero de 2006, la denuncia ante la Fiscalía del Tribunal Superior de Justicia de Murcia y la cobertura de los medios de comunicación del escándalo, sirvió para que, pese a las transacciones económicas en relación a la compra a bajo precio y posterior venta de los terrenos que aparecen secuencialmente en la Sentencia que comentamos, nunca llegase a 
producirse la urbanización efectiva de los terrenos, en su gran mayoría, como veremos, cultivos de secano y hábitats protegidos por la legislación europea, de gran valor ecológico por la presencia de tortuga mora, águila-azor perdicera, búho real y camachuelo trompetero.

La Sentencia de la Audiencia Provincial de Murcia (Sección Tercera), de 22 de diciembre de 2017 (ponente: María Concepción Roig Angosto), once años después de la denuncia de los hechos, tras una instrucción compleja y extensa, en la que se han producido dilaciones indebidas, y un juicio oral tenso y complicado, se ocupa en sus 331 folios de analizar el contexto normativo y jurisprudencial urbanístico y ambiental del caso, el íter comisivo de los diferentes acusados y la intervención de numerosos funcionarios y autoridades.

Pese a que la Sentencia no es definitiva, y nos consta que se han presentado recursos de casación, hemos considerado oportuno acercarnos al relato fáctico y probatorio consignado en la resolución judicial. Los hechos probados demuestran que el buen funcionamiento de la Administración ambiental y urbanística, base de la confianza que se deposita por todos en la eficacia del Derecho Ambiental, cede ante casos concretos, y en los que un grupo reducido de autoridades y funcionarios, pone en jaque a toda una Administración, compuesta en su mayoría por probos funcionarios de carrera. Algunos de estos funcionarios han sido represaliados internamente, por su comportamiento en el relato de los hechos, negándose a actuar con los ahora declarados delincuentes, y por su posterior colaboración con la Justicia en intensas declaraciones testificales que han sido fundamentales para desmontar las teorías esgrimidas en su defensa por los acusados, que, señalaremos, en su mayoría son profundos conocedores del Derecho urbanístico y ambiental vigente $\mathrm{y}$, por lo tanto, hábiles componedores de falacias aparentemente consistentes. Todas ellas han tenido que ser desmontadas acudiendo a un elaborado discurso jurídico, primero las acusaciones y luego las juzgadoras, en el que se han visto analizados diferentes institutos del Derecho Administrativo Ambiental. 
Ejercieron la acusación popular las dos grandes organizaciones ecologistas de la Región murciana ("Ecologistas en Acción" y "Asociación de Naturalistas del Sureste") y el partido mayoritario de la oposición - PSOE -, partes a las que les ha sido reconocido en Sentencia su buen hacer, su gran trabajo de acusación junto al Ministerio Fiscal aportando argumentos, pruebas documentales y periciales cruciales para entender el desastre ambiental que podía haberse originado en la finca de la Zerrichera, de alta sensibilidad ecológica. El reconocimiento de las acusaciones populares se observa en la condena a pagar sus costas por tres de los cinco acusados que han sido finalmente condenados y la referencia a la Sentencia del Tribunal Supremo 1318/2005, de 17 de noviembre, referida a la loable participación altruista como acusación popular de la "Asociación Proyecto Sierra de Baza".

Para entender las dimensiones del caso Zerrichera es necesario referir que afecta a dos Administraciones: el Ayuntamiento de Águilas, municipio costero, y la Comunidad Autónoma de la Región de Murcia, a través de dos centros directivos, la Consejería con competencias en Medio Ambiente y la Consejería con competencias en Ordenación del Territorio. El conocimiento y tramitación ante dichas entidades administrativas son necesarios para la reclasificación de una finca enclavada en suelo no urbanizable a través de una modificación puntual del Plan General de Ordenación Urbana. Esta alteración de la planificación urbanística requiere, a su vez, de una Evaluación de Impacto Ambiental (en adelante, EIA), y, por situarse en terrenos de la Red Natura 2000, de una evaluación de repercusiones conforme a la legislación europea. Precisamente, estas herramientas preventivas de protección ambiental, la EIA y la evaluación de repercusiones, fueron clave en la comisión de los delitos que se analizan en la Sentencia por cuanto que fueron falseadas por algunos de los acusados y perdieron su efecto de garantía de indemnidad de los bienes ambientales, en este caso, los objetivos de conservación del Lugar de Interés Comunitario y la Zona de Especial Protección para las Aves a los que pertenece la finca en cuestión. A lo anterior se suma la contradicción de la modificación del planeamiento sobre la finca con lo dispuesto en el Plan de Uso 
y Gestión de dichos espacios naturales que se venía tramitando en la Dirección General de Medio Natural de la Consejería con competencias en materia de medio ambiente, que debía haber sido aprobado en junio de 2004 pero que se retrasó hasta 2010.

El expediente administrativo para la reclasificación de la finca de la Zerrichera comenzó mediante un avance de la modificación puntual del plan general de ordenación urbana del municipio de Águilas como fruto de un convenio urbanístico firmado con el Grupo Inversor Hispania. Tras ser enviado dicho avance a la Consejería con competencias en materia de medio ambiente, el Ayuntamiento recibió un informe negativo por parte de la Dirección General de Medio Natural que calificó de incompatible la reclasificación para una urbanización de 4.000 viviendas con campo de golf con los objetivos de conservación del LIC y la ZEPA sobre la finca en cuestión. El Ayuntamiento de Águilas archivó el expediente, pese a las protestas del Grupo Inversor Hispania que acudió sin éxito a la Comisión Europea en un intento de desclasificar la finca Zerrichera.

Si bien la finca había sido roturada para llevar a cabo agricultura intensiva de lechuga en 32 hectáreas, tales agresiones a los hábitats protegidos fueron denunciadas por la guardia civil (SEPRONA) y la organización no gubernamental "Ecologistas en Acción" en 2002 y 2003 respectivamente, y, como se reitera una y otra vez en la resolución judicial, tales desmanes debieron haber sido sancionados por la Consejería con competencias en medio ambiente y haberse impuesto la obligación de restaurar a su estado anterior o haberse restaurado a cosa de los infractores. Pese a todo, las especies protegidas en el área podían seguir utilizando tales zonas como áreas de campeo, como fue ratificado por los peritos en el juicio oral y demostraba la ejecución de un Proyecto LIFE para la conservación del águila-azor perdicera en la zona. El Tribunal penal se posiciona claramente en contra de una estrategia de degradación comúnmente utilizada en suelos protegidos como fue la plantación de lechugas en los terrenos de secano pertenecientes al LIC y la ZEPA. 
Entre las acciones atribuidas a los tres acusados y condenados por el delito de prevaricación general se incluyen aquellas que tienen como objeto revertir la situación anterior mediante un intento de desclasificación de la finca como LIC y ZEPA desde la Dirección General de Medio Natural y ante el Ministerio de Medio Ambiente por inexistente motivos técnicos y cartográficos; $y$, lo que se considera más grave, reiniciar el expediente de reclasificación del Ayuntamiento de Águilas desde la Dirección General de Calidad Ambiental de la Consejería con competencias en medio ambiente provocando la aprobación inicial del mismo y acelerando los trámites a través de diversas irregularidades en el proceso de Evaluación de Impacto Ambiental para soslayar el informe preceptivo y la evaluación de repercusiones que tenían que ser emitidos por los técnicos de Medio Natural - contrarios a la reclasificación del suelo por su contradicción con el Plan de Gestión de la ZEPA en trámite - y que fueron emitidos en una tarde por personal de la Administración con formación en química en un informe "ad hoc", arbitrario y fraudulento basado con la técnica del "corta y pega" en estudios aportados por el Grupo Inversor, así como, finalmente, falsificar la Declaración de Impacto Ambiental tras actuaciones irregulares ante la Comisión de Evaluación de Impacto Ambiental, que nunca dio su parecer favorable, sino condicionado.

El expediente urbanístico y sustantivo de reclasificación de la Zerrichera, una vez obtenida la Declaración de Impacto Ambiental, pasó del Ayuntamiento de Águilas a la Dirección General de Vivienda, Arquitectura y Urbanismo de la Consejería de Obras Públicas, Vivienda y Transportes, donde dos acusados más - autoridades del área - informaron favorablemente su aprobación, pese a la condición de suelo no urbanizable, la ausencia de interés público y el informe contrario por falta de disponibilidad de recursos hídricos de la Confederación Hidrográfica del Segura. Éstos no han sido finalmente condenados en la Sentencia que comentamos por cuestiones formales relativas a su influencia sobre el Consejero que finalmente aprobó definitivamente. 
Otra de las cuestiones más llamativas de la Sentencia que analizamos es el posicionamiento de Derecho urbanístico que realiza el Tribunal penal, que incluso llega a interpretar normas del Tribunal Constitucional en la materia y en relación con la clasificación del suelo no urbanizable tras su selección como integrante de la Red Natura 2000, de forma contraria a los informes jurídicos aportados al expediente urbanístico de la reclasificación. Asímismo, se afirma de forma cabal en la Sentencia "parece evidente que antes que establecer en el documento urbanístico (Modificación de Plan General) que los terrenos podían urbanizarse, era necesario, dada su condición de protegidos, que el documento medioambiental específico para ello (el Plan de Uso y Gestión), estableciera de forma clara qué usos eran posibles y cuáles no, con independencia del modo de gestión posterior."

Fruto de lo anterior, y de otros posicionamientos del Tribunal penal, quedan en evidencia la gran mayoría de asesores jurídicos de las Consejerías citadas que realizaron informes con contenidos o bien cercanos a la falacia o bien acomodados a los pasos que los acusados iban dando, actos por los que no han respondido en sede penal. Esta afirmación es predicable de otras autoridades que habiendo o no participado como testigos, quedan en entredicho por sus irregulares intervenciones en los hechos, tanto dentro de la Comisión de Evaluación de Impacto Ambiental como fuera de ella. Así, la condena final es mínima en comparación con lo que podría haberse sentenciado si hubieran sido acusados todos los intervinientes en la trama.

También resulta llamativa la intervención del representante de la organización no gubernamental Fundación Global Nature en Murcia, presente a través de proyectos de custodia del territorio en la zona de la finca de la Zerrichera, que compareció en el trámite de información pública y afirmó mediante informe incorporado posteriormente - la compatibilidad de la reclasificación con la protección de los valores ecológicos presentes. Como colofón a las artimañas utilizadas se afirma en la Sentencia la manipulación por parte de algunos de los acusados de los informes emitidos por profesores universitarios de Madrid y 
Almería a la hora de influir favorablemente en la reclasificación y favorecer los intereses particulares del grupo inversor.

Uno de los retos más importantes en el enjuiciamiento penal de los hechos y las responsabilidades en este caso ha sido la sólida formación jurídica, ambiental y urbanística de los acusados, que urdieron su trama con una lógica aparente y la han defendido en juicio, mezclando conceptos para favorecer interpretaciones favorables a la urbanización de la finca, intentando confundir a las acusaciones y a los juzgadores, que han realizado un encomiable trabajo en desenredar los innumerables actos jurídicos con apariencia de legalidad pero que escondían la intención de burlar la vis protectora de las normas ambientales.

El caso de la Zerrichera es una suerte de catálogo de actuaciones posibles por parte de autoridades y funcionarios que, con objeto de beneficiar intereses particulares concretos de un grupo de inversión, y apartándose de los intereses generales a los que debían su cargo, pueden generar una legalidad falsa y un artificio que dé al traste con el sistema preventivo y proyectos de los espacios naturales de la Red Natura 2000 del que es pieza clave la EIA y la evaluación de repercusiones, y el análisis técnico que por parte de la Administración ambiental debe realizarse de los estudios aportados por el promotor. Como afirma la Sentencia, "es evidente que cuando el legislador ordena que se haga un estudio y análisis de los informes sobre evaluación de repercusiones presentados por los interesados es porque no es extraño que, cuanto menos, no se correspondan con la realidad". Asímismo extractamos: "los acusados convirtieron en ilusorio el control que exige la legislación y la jurisprudencia en el procedimiento de evaluación de impacto ambiental, y dieron lugar a que se produjera una resolución arbitraria e injusta por perjudicial tanto para el hábitat contenido en el LIC como para la avifauna de la ZEPA existente en la Finca La Zerrichera". 
Por último, en relación con el delito concreto al que se enfrentan los acusados, se expresa: "con la regulación y aplicación del delito de prevaricación no se pretende sustituir a la jurisdicción administrativa, en su labor de control de la legalidad de la actuación de la Administración Pública, por la jurisdicción penal, sino sancionar supuestos limite, en los que la actuación administrativa no solo es ilegal, sino además injusta y arbitraria". Una de las dificultades de la subsunción en el delito era la consideración de "resolución" de la Declaración de Impacto Ambiental" a los efectos del tipo, lo que se supera acudiendo a doctrina del propio Tribunal Supremo que recuerda que "si bien la DIA no supone la declaración última de la voluntad de la Administración, sí encierra esa declaración de voluntad última en el ámbito de la competencia de medio ambiente". "La gravedad del delito por el que condenamos a los tres acusados queremos resaltarla citando la STS 259/2015 de 30 de abril que, en relación con la penalidad, nos recuerda que pocas dudas pueden albergarse, y menos en el momento actual en el que la reacción social frente al fenómeno de la corrupción política y administrativa está a la altura de la relevancia de esta lacra, respecto de la necesidad de que los gestores públicos gocen de la confianza y del respeto de los ciudadanos. Y si para ello es exigible una cierta ejemplaridad social a quien ejerce cualquier función pública, con más intensidad debe hacerse respecto de aquellos cargos cuya función consiste precisamente, en ser representantes de los ciudadanos, consideraciones de la sentencia que citamos que en el caso podemos hacer extensivas a quienes son nombrados por dichos representantes, como ocurre en el caso de los tres acusados y condenados."

Por todo lo anterior recomendamos, aunque sea una ardua tarea, leer la extensa Sentencia que "pretende identificar con absoluta claridad el plano de la legalidad administrativa" y se convierte en una lección práctica de urbanismo y medio ambiente, así como estar pendiente del resultado de los recursos de casación iniciados. 


\section{EL FRACASO DE LA JURISDICCIÓN PENAL ANTE LA CONTAMINACIÓN DEL RÍO SEGURA A SU PASO POR LA CIUDAD DE MURCIA A FINALES DEL SIGLO XX.}

La siguiente resolución judicial, Sentencia número 347/2017, de 1 de diciembre de la Audiencia Provincial (Sección Segunda) de Murcia, (ponente: Enrique Domínguez López), puso fin a un procedimiento criminal por delito ecológico que desde su denuncia hasta la celebración del juicio oral se había extendido durante diecinueve años. Se trata pues de un claro despropósito procesal, tanto para los acusados - ocho en total, habiendo fallecido dos antes de la celebración del juicio -, como para el medio ambiente afectado, el río Segura a su paso por la ciudad de Murcia. La actual operación de restauración ambiental - que los más críticos califican de cosmética - del río Segura a su paso por la capital de la Región, donde mediante una represa se ofrece la imagen de un río caudaloso, ha hecho olvidar episodios de vergüenza colectiva por el paso de aguas contaminadas orgánicamente en los años 80 y 90 del siglo pasado, en lo que se consideró como una catástrofe ambiental. Precisamente en ese momento de vertidos y espumas y ante la clara inactividad de las Administraciones competentes, ocupadas en gestionar las ayudas europeas para depuradoras municipales sin atender a su efectivo funcionamiento, se produjo una denuncia de dos concejales del grupo Izquierda Unida ante el Juzgado de Guardia de Murcia por los vertidos que se producían al Río. La denuncia, pese a su pertinencia, adolecía de experiencia en materia de delito ecológico, prácticamente se estrenaba con un asunto "estrella" en los tribunales murcianos, y por evidente desconocimiento le faltó concretar los vertidos, si bien se apuntaba la responsabilidad a la empresa municipal de aguas (EMUASA) de Murcia.

La jueza encargada de la Instrucción penal, dependiente de lo que pudiera informar la Guardia Civil tras sus análisis in situ, inició una investigación que ahora la Audiencia Provincial considera, de acuerdo con las defensas, como "inquisición general". Dicha investigación, basada en tomas de muestras indiscriminadas aguas arriba y abajo del municipio de Murcia, afectó a otros partidos judiciales y mostró una realidad muy variada en cuanto a vertidos, 
causas y orígenes. Es decir, pese a que la denuncia se dirigía contra los responsables del tratamiento y depuración de aguas residuales en el Ayuntamiento de Murcia, la instrucción se amplió a multitud de frentes de forma expansiva derivando en una "causa general" por el lamentable estado del Río Segura. A lo anterior se sumó la ausencia de envío a reparto de los hechos comprobados mediante atestados que tenían que ver con responsabilidades distintas a las denuncias por causa del lugar de los hechos o las causas de los mismos, la falta de toma de declaración de los imputados y la expansión incriminatoria.

Ahora bien, el Auto de transformación a procedimiento abreviado y algunos escritos de acusación sí concretaron la acusación en base a los vertidos producidos a través de dos depuradoras, una antigua que nunca llegó a funcionar en Beniaján, y a la que se enviaron de forma irregular los vertidos del municipio de Alcantarilla, y otra nueva, en el Rincón de Gallego, que en sus inicios estuvo vertiendo directamente agua contaminadas desde diversos azarbes conectados a la red de acequias. Todos los vertidos contaban con autorización provisional de la Confederación Hidrográfica del Segura, que, conocedora de la situación por la existencia de denuncias de la Guardería Fluvial, lejos de sancionar, renovó las autorizaciones y consintió los hechos. Por todo ello fueron acusados el Alcalde de Alcantarilla, los Presidentes y Comisarios de Aguas de la Confederación Hidrográfica del Segura, el Gerente de EMUASA, y dos técnicos.

Pero la Sentencia que comentamos no entra en el fondo del asunto, se limita a aplicar el instituto de la prescripción por motivo de que la instrucción estuvo injustificadamente paralizada durante más de cinco años, que es el plazo de prescripción del delito ecológico por el que fueron finalmente acusadas las partes, y a determinar la absolución de todos los acusados.

En otro apartado, y en relación con la nulidad del procedimiento, hace referencia a la "causa general", ya mencionada anteriormente. 
La instrucción de esta causa pasará a la historia de las causas judiciales ambientales de la Región de Murcia, puesto que la maquinaria procedimental y la ausencia de sensibilidad judicial con respecto a este asunto han permitido esta inhabitual duración de la instrucción y la fase intermedia. No obstante, al fracaso del Derecho Penal en esta materia, la acusación ejercitada durante todos estos años ha podido tener que ver con el cambio de actitud de los responsables de las Administraciones competentes. Sirva pues este ejemplo para añadir una frustración más a la vía penal e intensificar el debate acerca de si realmente es la más oportuna en procesos importantes de contaminación con multitud de responsables y focos, o debería acudirse a la vía de la responsabilidad medioambiental en base a la Ley 26/2007 y fortalecerla para estos casos.

La Sentencia que pone fin al dilatado proceso realiza ciertos comentarios finales en relación a la protección del medio ambiente y la situación del río Segura a finales del siglo pasado, partiendo del artículo 45 de la Constitución, para luego reconocer la justificación del proceso penal frustrado. "Concretamente, hace dos décadas, el que fuera denominado Río Blanco por los árabes, se encontraba en un estado lamentable desde kilómetros arriba del municipio de Murcia y hasta su desembocadura en Guardamar del Segura (vertidos, malos olores, suciedad, mortandad de fauna...), era algo más que evidente para cualquier persona que se acercara a su cauce y que, padecían fundamentalmente, los habitantes y agricultores de los municipios ribereños con evidente afectación a la salubridad y a las condiciones sanitarias de la población y el medio natural. Cierto es que en poco o nada se parece la situación actual del rio Segura a la que existía hace casi dos décadas, pero lo inaudito fue tener que llegar a ese estado de desastre medioambiental (como "cloaca a cielo abierto" fue calificado en diversas ocasiones, recogiéndose esta denominación en páginas oficiales) y a la incoación de diversos procedimientos judiciales (en muchos casos, como el que nos ocupa, a instancias de particulares y entidades de la Sociedad -Civil), para proceder a revertir la 
situación que padecía por vertidos de todo tipo en cientos de kilómetros del río Segura y de sus afluentes." 